\title{
Depressive symptoms predict increased social and emotional loneliness in older adults
}

Joanna McHugh Power, Caoimhe Hannigan, Philip Hyland, Sabina Brennan, Frank Kee \& Brian A. Lawlor

To cite this article: Joanna McHugh Power, Caoimhe Hannigan, Philip Hyland, Sabina Brennan, Frank Kee \& Brian A. Lawlor (2020) Depressive symptoms predict increased social and emotional loneliness in older adults, Aging \& Mental Health, 24:1, 110-118, DOI: 10.1080/13607863.2018.1517728

To link to this article: https://doi.org/10.1080/13607863.2018.1517728

册 Published online: 22 Oct 2018.

Submit your article to this journal $匚$

Џll Article views: 485

Q View related articles ¿

View Crossmark data \

4 Citing articles: 2 View citing articles 


\title{
Depressive symptoms predict increased social and emotional loneliness in older adults
}

\author{
Joanna McHugh Power ${ }^{\mathrm{a}, \mathrm{b}, \mathrm{c}}\left(\mathbb{D}\right.$, Caoimhe Hannigan $^{\mathrm{b}}$ (D) Philip Hyland $^{\mathrm{a}}$ (D), Sabina Brennan ${ }^{\mathrm{b}}$ (D), \\ Frank Kee ${ }^{\mathrm{c}}$ and Brian A. Lawlor ${ }^{\mathrm{b}}$ \\ ${ }^{a}$ School of Business, National College of Ireland, Dublin, Republic of Ireland; 'bnstitute of Neuroscience, Trinity College Dublin, Dublin, \\ Republic of Ireland; ' $U K$ CRC Centre of Excellence for Public Health, Queen's University Belfast, Belfast, United Kingdom
}

\begin{abstract}
Objectives: Explorations of relationships between loneliness and depression have focused on loneliness as a uni-dimensional construct. We hypothesised that reciprocal relationships may exist between depressive symptomatology and social and emotional subtypes of loneliness.

Methods: Using data from 373 adults aged over 50, who participated in an observational cohort study, we employed a cross-lagged approach within a Structural Equation Modelling framework, to investigate reciprocal links between depressive symptomatology, and social and emotional loneliness, across two waves of data collection, two years apart (controlling for age, sex, education, comorbidities, social network index, and perceived stress).

Results: Both depressive symptomatology and loneliness decreased slightly between waves. Autoregressive effects were strong for all three variables of interest. Cross-lagged pathways were evident, such that depressive symptomatology at baseline predicted both emotional $(\beta=0.26$, $p<0.05)$ and social $(\beta=0.17, p<0.05)$ loneliness at follow-up. Neither emotional $(\beta=0.07$, $p>0.05)$ nor social $(\beta=0.05, p>0.05)$ loneliness at baseline predicted depressive symptomatology at follow-up.

Conclusions: Results challenge existing understanding of the associations between loneliness and depression. Further investigation of emotional and social loneliness in individuals with depressive disorders is warranted. Findings are discussed in relation to mechanisms that may explain the relationships observed, and possible implications.
\end{abstract}

\section{ARTICLE HISTORY}

Received 18 March 2018 Accepted 24 August 2018

\section{KEYWORDS}

Emotional loneliness; social Ioneliness; structural equation modelling; cross lagged path modelling; depressive symptomatology; ageing
Despite their strong relationship, loneliness and depression are distinct phenomena (Adams, Sanders, \& Auth, 2004), with loneliness typically defined in relation to discrepancies between actual and desired social contact (Perlman \& Peplau, 1982) and depression referring to a more global mood disorder (American Psychiatric Association, 2013). Loneliness is thought to affect a minority of older adults (Victor \& Bowling, 2012), while depression is one of the commonest mental health issues faced by older adults, with $28 \%$ of older Irish adults reporting levels indicative of clinically significant or sub-threshold depression (Barrett et al., 2011). The association between loneliness and depression appears to remain stable across the lifespan (Nolen-Hoeksema \& Ahrens, 2002). A commonly used psychometric scale of depression, the Centre for Epidemiological Studies Depression scale (CESD; (Radloff, 1977)) includes an item regarding loneliness, such is the extent of the relationship and possible overlap between these constructs. That said, only half of lonely individuals expressed depression symptoms in an older U.S. population (Donovan et al., 2017), signalling the relative independence of these two constructs.

Over time, high levels of loneliness predict depression (Cacioppo, Hawkley, \& Thisted, 2010; Dahlberg \& McKee, 2014; Heikkinen \& Kauppinen, 2004; O'Luanaigh \& Lawlor, 2008). There are many factors that may explain this association, such as poor sense of control (van Belijouw et al.,
2014), disordered coping styles (Vanhalst, Luyckx, Teppers, \& Goossens, 2012), and decreased social support (Liu, Gou, \& Zuo, 2016). Cacioppo has suggested that it is possible that loneliness predicts depression because of its association with numerous predictors of depression, including demographic factors, psychosocial factors, and perceived stress (Cacioppo, Hughes, Waite, Hawkley, \& Thisted, 2006) although his empirical findings (ibid.) suggest that loneliness predicts depression net of these factors.

Theoretically, there are also clear reasons to expect loneliness to lead to depression: Cacioppo's evolutionary theory of loneliness suggested that it functioned to create negative affect (which could result in depressed mood) in order to encourage the individual to maintain or repair social ties in the interests of survival (Cacioppo, Cacioppo, \& Boomsma, 2014). Later-life bereavement may also cause loneliness and subsequently depression (Fried et al., 2015), and alternatively loneliness may constitute a form of social stress that results in dysfunctional changes to the inflammatory (Steptoe, Owen, Kunz-Ebrecht, \& Brydon, 2004) and hypothalamus-pituitary-adrenal axis (Cacioppo et al., 2000). Horowitz' prototype model of loneliness suggests that because the prototype of loneliness sits within the broader prototype of depression, it is far more common for a lonely individual to report depression than for a depressed individual to report loneliness (Horowitz, de French, \& Anderson, 1982). 
Interestingly, depression also predicts loneliness (Dahlberg, Andersson, McKee, \& Lennartsson, 2015; Lasgaard, Goossens, \& Elklit, 2011; Mullins \& Dugan, 1990; Tiikkainen \& Heikkinen, 2005). Possible mechanisms underlying this relationship include an inability to maintain social networks, social disengagement (Allen \& Badcock, 2003; Tiikkainen \& Heikkinen, 2005) and functional impairment (Mehta, Yaffe, \& Covinsky, 2002; Pinquart \& Sorensen, 2001). Relationship disruptions such as break-ups may also cause both loneliness and depression, leading them to display a confounded relationship (Weeks, Michela, Peplau, \& Bragg, 1980).In the same manner, vascular dysfunction is thought to be caused by both loneliness (Hawkley, Thisted, Masi, \& Cacioppo, 2010) and depression (Thomas, Kalaria, \& O'Brien, 2004) and at the same time, both loneliness and depression (Thomas, Kalaria, \& O'Brien, 2004) are thought to cause vascular dysfunction in older adults. By the same token, comorbidities and functional limitations are known to be associated with both depression (Ho et al., 2014; Hybels, Pieper, \& Blazer, 2009) and loneliness (Shankar, McMunn, Demakakos, Hamer, \& Steptoe, 2017; Smith \& Victor, 2018).

As would be expected based on the above studies, other studies exploring bidirectional links between depression and loneliness have indicated that reciprocal relationships exist (Cacioppo et al., 2006; Vanhalst et al., 2012).

It is worth considering whether these patterns are shown when loneliness is considered as a bi-dimensional construct - as social and emotional loneliness subtypes (R. S. Weiss, 1973). Social loneliness reflects the felt absence of social networks while emotional loneliness is defined as the felt absence of an intimate partner. Empirical evidence exists for these two separate subtypes of loneliness rather than a single dimension (Van Baarsen, Snijders, Smit, \& Van Duijn, 2001), which only correlate moderately with each other (Green, Richardson, Lago, \& Schatten-Jones, 2001) sharing only $19 \%$ variance, further indicating that loneliness is not uni-dimensional (Dahlberg \& McKee, 2014).

Weiss hypothesised that of the two subtypes, social loneliness would be more likely to lead to depression (R. Weiss, 1974), an hypothesis which was later corroborated by empirical findings (DiTommaso \& Spinner, 1997; George, 1989). Other data suggest that emotional loneliness alone is associated with depression (Peerenboom, Collard, Naarding, \& Comijs, 2015; Schnittger, Wherton, Prendergast, \& Lawlor, 2012), but yet other researchers found both subtypes to be related to depression (Drageset, Espehaug, \& Kirkevold, 2012).

More longitudinal research is needed if we are to understand the independent relationships between subtypes of loneliness and depression. As such, an investigation of associations between depression and emotional and social loneliness over time (which, to our knowledge, has not yet been conducted) is warranted. It is likely that both social and emotional loneliness will be associated with depression. What is less clear is the extent to which the subtypes of loneliness predict depression, or whether the existence of cross-lagged paths, between depression and subtypes of loneliness, is more plausible. Credible mechanisms are apparent for both. It is possible that emotional loneliness predicts depression because of its association with higher levels of neuroticism and lower levels of self-mastery (Peerenboom et al., 2015).

Alternatively, it is possible that emotional loneliness may be caused by depression, in that depression may affect attachment, intimacy, and family contact, all of which are predictors of emotional loneliness (DiTommaso \& Spinner, 1997; Drennan et al., 2008; Essex, Klein, Lohr, \& Benjamin, 1985; Pettem, West, Mahoney, \& Keller, 1993). Decreasing social support (which could be related to either social or emotional loneliness) has previously been suggested to mediate an association between loneliness and depression (Liu et al., 2016). Alternatively, depression may precede social withdrawal (Allen \& Badcock, 2003; Tiikkainen \& Heikkinen, 2005), which could cause social loneliness.

We hypothesised that there would be reciprocal effects between a) depressive symptoms, and b) both subtypes of loneliness (emotional and social), among a cohort evaluated across a two-year, two-wave period.

\section{Methods}

\section{Design}

An observational, longitudinal study design was employed. The aim of the broader study (entitled the Memory Research Unit) was to evaluate biopsychosocial factors related to cognitive decline in later life (Hannigan, Coen, Lawlor, Robertson, \& Brennan, 2015). The current analysis focused on data pertaining to loneliness and depressive symptomatology specifically as a secondary data analysis. Follow-up information was gathered from participants 2 years later. The study was approved by the university research ethics committee.

\section{Participants}

Of the 946 community-dwelling adults aged over 50 evaluated at baseline (2012), all participants gave written informed consent to participate in the study. Participants were eligible to participate if they were over 50 , resident in the Republic of Ireland, sufficiently fluent in English, in good health, and able to attend the assessment centre. Participants were not eligible to participate if they reported any of the following: history of stroke, epilepsy, major psychiatric disorder (evaluated with the question "In the last 5 years have you been hospitalised for a psychiatric condition?" not including anxiety or depression), drug or alcohol abuse within the past 5 years, current use of antipsychotic or antiepileptic medication, self-report of significant memory problems or dementia, or problems with vision or hearing that would prevent neuropsychological evaluation. In total, 82 individuals were excluded from the study because they met one or more of the above listed exclusion criteria.

Participants were recruited via convenience sampling, using a number of strategies including advertisements, articles in the local and national media, and community information sessions provided by the study team.

Because of resource issues, the goal was to target $50 \%$ of the original cohort to return for follow-up. The 490 who were contacted for follow-up as a result were selected in chronological order related to the time at which their 
baseline examination was conducted, to maintain a 2-year gap between the two testing periods. No differences were found between those who were contacted for follow-up and those who were not in terms of their age $(\mathrm{t}=-0.06$, $\mathrm{df}=820, p>0.05)$, gender $\left(\chi^{2}=0.07, \mathrm{df}=1, p>0.05\right)$ educational attainment $(\mathrm{t}=-1.95, \mathrm{df}=904, p>0.05)$, loneliness $(\mathrm{t}=0.66, \mathrm{df}=763, p>0.05)$, depressive symptomatology $(\mathrm{t}=0.54, \mathrm{df}=752, p>0.05)$, and cognitive functioning $(\mathrm{t}=-1.05, \mathrm{df}=550, p>0.05)$. Of these 490 contacted, 373 returned for follow-up, meaning that the retention rate was $76.12 \%$ (and these 373 individuals did not in turn differ in the above variables to the 490 contacted). The remaining $23.88 \%(n=117)$ comprised 63 refusals, 53 lost to follow-up, and one death.

\section{Measures}

To evaluate loneliness, continuous scores on the De Jong Gierveld scale of loneliness was used (de Jong Gierveld \& van Tilburg, 2006). This six-item scale was developed to evaluate social and emotional loneliness among older adults. The three items evaluating social loneliness include: "There are plenty of people I can rely on when I have problems" and "There are enough people I feel close to". The three items evaluating emotional loneliness include: "I experience a general feeling of emptiness" and "I miss having people around". Respondents must indicate a response of yes or no to all six items. Scores range from 0-6, with higher scores indicating greater loneliness.

Reliability (Cronbach's alpha) has consistently been shown to be above 0.8 in both subscales (Gierveld \& Van Tilburg, 2010). Depressive symptoms were measured using continuous scores on the 20-item Centre for Epidemiological Studies Depression scale (Radloff, 1977) calculated to exclude the item on loneliness. This scale can be used to evaluate unidimensional depression (Edwards, Cheavens, Heiy, \& Cukrowicz, 2010). Scores range from 0-60, with higher scores indicating greater depressive symptoms.

Reliability for the emotional loneliness subscale was low (emotional loneliness: alpha $=0.54$ in wave 1 , alpha $=0.56$ wave 2) but just below criterion for social loneliness (alpha $=0.79$ in wave 1, 0.75 wave 2). These values are similar to those previously reported (Dahlberg \& McKee, 2014), and because these scales are short, these authors advise focusing on the outcome of the measurement model (i.e. the factor loadings of each item within these two subscales, see Table 2) rather than on measures of reliability such as the Cronbach's alpha. Thus, loneliness was described in the model as a latent factor. Reliability of the CESD (excluding the item on loneliness) was better at alpha $=0.83$ at wave 1 , and 0.82 at wave 2 .

While covariates are frequently omitted from crosslagged panel model analysis, they are important to use if it is thought that they will confound the association between the variables of interest (Newsom, 2016). Age, sex, scores on the Berkman-Syme Social Network Index (Berkman \& Syme, 1979) [inclusive of marital status, which was included in Cacioppo's analysis, having at least two individuals the participant feels close to, attending religious meetings at least once per month, and membership of a social group, yielding final scores ranging from $0-4$, with higher scores indicating greater social connectedness], level of education (such that participants were categorised as receiving less than a high school equivalent, high school equivalent, or third level/tertiary/postsecondary education and higher: that is, a qualification received within a university, college, or trade school), physical functioning, and perceived stress (using the 4-item Perceived Stress Scale; (Cohen, Kamarck, \& Mermelstein, 1983) were added as covariates. The measure of physical functioning was approximated in the current study using a health screen questionnaire (Christensen, Moye, Armson, \& Kern, 1992) which asked participants to self report if they had a history of the following: cancer other than skin cancer, diabetes, heart attack, lupus, liver disease, use of home oxygen, and hypertension that is not well controlled. A comorbidity count was created from these items.

\section{Data analysis}

To evaluate potential reciprocal effects between loneliness subscales and depressive symptomatology across two waves, we used the cross-lagged panel modelling approach within a structural equation modelling (SEM) framework. Typically, exploring cross-lagged effects requires a comparison between an initial model containing auto-regressive effects only, and a follow-up model including cross-lagged effects of interest (Hyland et al., 2015). These models were run using the maximum likelihood estimator (with robust standard error estimation and a full information maximum likelihood approach to missing data) in the lavaan package in R software (Rosseel, 2012). Covariates were included in all models as exogenous variables predicting the variables of interest in wave 1, which also accounts for residual correlation between these variables at wave 1. Model 2 adds cross-lagged paths (i.e. the pathway between subtypes of loneliness at wave 1 and depressive symptomatology at wave 2 , and the pathway between depressive symptomatology at wave 1 and subtypes of loneliness at wave 2), and model fit across models 1 and 2 is compared. If model fit is superior in the second model, this can be attributed to the inclusion of the cross-lagged paths.

Within waves, residual correlations are constrained to be equal. In order to compare model fit, three criteria are used: the Akaike Information Criterion (AIC), and the sample size adjusted Bayesian Information Criterion (ssaBIC). Both criteria are relative measures of model fit, designed to compare models. Both indicate a better fit when scores are lower, while at the same time favouring parsimony. The ssaBIC adjusts for sample size, and all three adjust for the number of estimated parameters in the model. The ssaBIC is thought to be particularly informative when choosing between models (Enders \& Tofighi, 2008).

Model fit of each individual model was evaluated in an absolute manner (as opposed to the relative evaluation afforded by the above three criteria) using a number of standard SEM indices including the Confirmatory Fit Index (CFI) which compares the chi square statistic of the specified model to that of a null model in a ratio (which, to indicate goodness of fit, should be over 0.9). The Tucker Lewis Index (TLI) is similar to the CFI but is independent of sample size and penalises model complexity. It should also be over 0.9. The root mean square error of approximation 
Table 1. Sample characteristics for $n=373$ participants who were evaluated at waves 1 and 2 of the Memory Research Unit study (SD $=$ Standard Deviation; comorbidity using the Health Screen Questionnaire (Christensen et al., 1992)).

\begin{tabular}{|c|c|}
\hline Variable & Mean (SD) or Frequencies (\%) \\
\hline Age & $64.33(6.9)$ \\
\hline Sex & $63 \%$ female; $37 \%$ male \\
\hline Marital status & $27 \%$ not married/cohabiting $73 \%$ married/cohabiting \\
\hline Years of education & $\begin{array}{l}14.84(S D=3.5) 4 \% \text { less than second level education } 48.6 \% \text { second level } \\
\text { education } 47.4 \% \text { third level education or higher }\end{array}$ \\
\hline Berkman syme social network index & $\begin{array}{l}3.08(S D=0.79) 3 \% \text { very isolated } 19 \% \text { moderately isolated } 46 \% \text { moderately } \\
\text { integrated } 32 \% \text { very integrated }\end{array}$ \\
\hline Emotional loneliness & Wave 1: $0.54(S D=0.81)$; Wave 2: $0.46(S D=0.77)$ \\
\hline Social loneliness & Wave 1: $0.36(S D=0.81)$; Wave 2: $0.34(S D=0.78)$ \\
\hline Depressive symptoms (without loneliness item) & Wave 1: $6.09(\mathrm{SD}=5.99) ;$ Wave 2: $5.53(\mathrm{SD}=5.5)$ \\
\hline
\end{tabular}

Table 2. Model 2: Auto-regressive and cross-lagged paths (with exogenous covariates age, sex, and perceived stress) for Waves 1 and 2 Emotional Loneliness and Depression, with measurement model components for the latent factors of a) Emotional Loneliness at Wave 1, and b) Emotional Loneliness at Wave 2. Robust standard errors were reported throughout.

\begin{tabular}{|c|c|c|c|c|}
\hline & Beta/factor loading & Standard error & Z & $p$ \\
\hline \multicolumn{5}{|c|}{ Measurement model: Emotional loneliness At Wave 1} \\
\hline Item 1 & 0.83 & 0.03 & 9.20 & $<0.001$ \\
\hline Item 2 & 0.31 & 0.03 & 4.53 & $<0.001$ \\
\hline Item 3 & 0.71 & 0.03 & 6.96 & $<0.001$ \\
\hline \multicolumn{5}{|l|}{ Emotional loneliness at Wave 2} \\
\hline Item 1 & 0.67 & 0.03 & 4.44 & $<0.001$ \\
\hline Item 2 & 0.49 & 0.03 & 4.82 & $<0.001$ \\
\hline Item 3 & 0.63 & 0.03 & 4.63 & $<0.001$ \\
\hline \multicolumn{5}{|l|}{ Autoregressive and cross-lagged paths } \\
\hline \multicolumn{5}{|c|}{ Emotional loneliness (Wave 2 ) as outcome } \\
\hline Emotional loneliness at Time 1 & 0.52 & 0.24 & 2.66 & $<0.01$ \\
\hline Depressive symptomatology at Time 1 & 0.26 & 0.03 & 1.99 & $<0.05$ \\
\hline \multicolumn{5}{|c|}{ Depressive symptomatology (Wave 2) as outcome } \\
\hline Depressive symptoms at Time 1 & 0.54 & 0.10 & 5.02 & $<0.001$ \\
\hline Emotional loneliness at Time 1 & 0.07 & 0.49 & 0.74 & $>0.05$ \\
\hline \multicolumn{5}{|c|}{ Regression paths from covariates: With emotional loneliness (wave 1 ) as the outcome } \\
\hline Age & -0.02 & 0.01 & -0.30 & $>0.05$ \\
\hline Education & -0.16 & 0.12 & -2.64 & $<0.01$ \\
\hline Sex & 0.04 & 0.14 & 0.57 & $>0.05$ \\
\hline Social network index & 0.01 & 0.09 & 0.13 & $>0.05$ \\
\hline Comorbidities & 0.13 & 0.26 & 1.74 & $>0.05$ \\
\hline Perceived Stress & 0.43 & 0.04 & 5.07 & $<0.001$ \\
\hline \multicolumn{5}{|c|}{ Regression paths from covariates: With depressive symptomatology (wave 1 ) as the outcome } \\
\hline Age & 0.02 & 0.04 & 0.43 & $>0.05$ \\
\hline Education & -0.07 & 0.47 & -1.61 & $>0.05$ \\
\hline Sex & -0.06 & 0.51 & -1.51 & $>0.05$ \\
\hline Social network index & -0.003 & 0.35 & -0.07 & $>0.05$ \\
\hline Comorbidities & 0.12 & 0.98 & 2.39 & $<0.05$ \\
\hline Perceived Stress & 0.62 & 0.15 & 10.14 & $<0.001$ \\
\hline
\end{tabular}

(RMSEA) describes the differences between corresponding elements of the observed and predicted covariance matrices and should be less than 0.05 . The standardised root mean square residual (SRMR) is also reported, which transforms both predicted and observed covariance matrices into correlation matrices and then describes the average magnitude of discrepancies between observed and expected correlations as an absolute measure of model fit [values should be less than 0.08; (Hu \& Bentler, 1999)].

\section{Results}

Sample characteristics are below in Table 1. Generally, the sample was healthy and socially integrated, with a relatively high level of education. The average score on the CESD scale was 6.09 at wave 1 , and 5.53 at wave 2, both well below the cut-off for clinical depression at 15 (Radloff, 1977), although it should be taken into account that the CESD as it was currently used only had 19 items since the item about loneliness was removed. The average CESD score found in a random sample of adults aged over 65 in the USA was 8 (Cole, Kawachi, Maller, \& Berkman, 2000), meaning that the current sample were marginally less depressed than an older USA sample of adults (taking into account the removal of the loneliness item). Scores of emotional loneliness yielded an average of 0.54 (wave 1) and 0.46 (wave 2), lower than those from across seven UN countries (0.63 - 1.48), while scores of social loneliness yielded an average of 0.36 (wave 1) and 0.34 (wave 2), also lower than those yielded in the same seven countries $(0.95$ - 2.27) (Gierveld \& Van Tilburg, 2010).

The cross-lagged path model approach was taken to evaluate reciprocal relationships first between emotional loneliness and depressive symptomatology, and second, between social loneliness and depressive symptomatology. Initially, a model with all three variables was included, but multi-collinearity between each subtype of loneliness and overall loneliness was problematic (see Supplementary Materials Table 1 for a correlation matrix of all key variables), so this alternative approach was taken instead. 
Wave 1

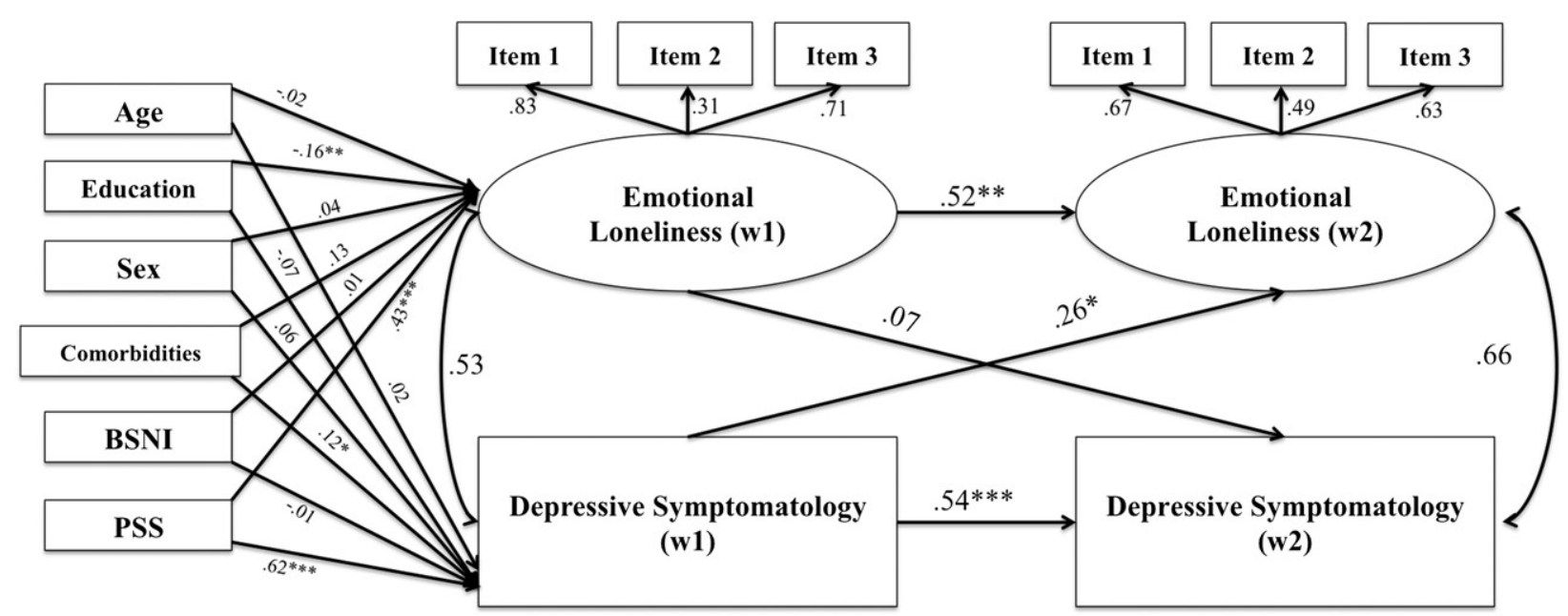

Figure 1. Pathways between baseline and follow-up measures of emotional loneliness, and depressive symptomatology (all presented statistics except withinwave covariances are standardised coefficients, whereby ${ }^{*}=p<0.05 ; * *=p<0.01 ; * * *=p<0.001$. If no asterisks are attached to the coefficient, it did not reach statistical significance).

\section{Emotional loneliness and depressive symptomatology}

Model 1: autoregressive paths only

Covariates were included as exogenous variables predicting baseline emotional loneliness, and depressive symptomatology. The model converged normally after 112 iterations. Model fit was good $\left[\chi_{54}^{2}=85.35, p<0.01 ; \chi^{2}{ }_{76}=558.52, p\right.$ $<0.001 ; \mathrm{CFI}=0.94 ; \mathrm{TLI}=0.91 ; \mathrm{RMSEA}=0.044\left(\mathrm{Cl}_{95}=0.028\right.$, $0.060), \mathrm{SRMR}=0.046 ; \mathrm{AIC}=9410 ; \mathrm{ssaBIC}=9429]$. The measurement model indicated acceptable loadings. Emotional loneliness $(\beta=0.73, p<0.001)$ and depressive symptomatology $(\beta=0.56, p<0.001)$ were both relatively stable across waves.

\section{Model 2: cross-lagged paths added}

The model converged normally after 125 iterations. Model fit was good $\left[\chi_{52}^{2}=78.78, p<0.05 ; \chi^{2}{ }_{76}=558.52, p<\right.$ $0.001 ; \mathrm{CFI}=0.94 ; \mathrm{TLI}=0.92 ; \mathrm{RMSEA}=0.042\left(\mathrm{Cl}_{95}=\right.$ $0.024,0.058), \mathrm{SRMR}=0.041 ; \mathrm{AIC}=9404 ; \mathrm{ssaBIC}=9425]$. The measurement model indicated acceptable loadings (see Table 2).

Comparing the criteria values across models 1 and 2, fit was superior in model 2 . In relation to the cross-lagged panels, depressive symptomatology predicted emotional loneliness $(\beta=0.26, p<0.05)$. Emotional loneliness did not predict depressive symptomatology over time $(\beta=0.07, p$ $>0.05)$. Thus, there was evidence of unidirectional paths from depressive symptomatology to emotional loneliness, although each variable was itself highly stable across waves (see Figure 1).

\section{Social loneliness and depressive symptomatology}

Model 1: autoregressive paths only

The model converged normally after 118 iterations. Model fit was good $\left[\chi_{54}^{2}=81.28, p<0.05 ; \chi^{2}{ }_{76}=617.05, p<\right.$ $0.001 ; \mathrm{CFI}=0.95 ; \mathrm{TLI}=0.93 ; \mathrm{RMSEA}=0.041\left(\mathrm{Cl}_{95}=\right.$ $0.024,0.056)$, SRMR $=0.044 ; \mathrm{AIC}=9227 ; \mathrm{ssaBIC}=9247]$. Social loneliness $(\beta=0.53, p<0.001)$ and depressive symptomatology ( $\beta=0.59, p<0.001$ ) were both relatively stable across waves.

\section{Model 2: cross-lagged paths added}

The model converged normally after 127 iterations. Model fit was good $\left[\chi^{2}{ }_{52}=74.79, p<0.05 ; \chi^{2}{ }_{76}=617.05, p<0.001\right.$; $\mathrm{CFI}=0.96 ; \mathrm{TLI}=0.94 ; \mathrm{RMSEA}=0.038\left(\mathrm{Cl}_{95}=0.019,0.054\right)$, $\mathrm{SRMR}=0.037 ; \mathrm{AIC}=9222 ; \mathrm{ssaBIC}=9244$; see Table 3].

Comparing the criteria values across models 1 , fit was superior in model 2, again indicating the existence of cross-lagged pathways.

Depressive symptomatology predicted social loneliness $(\beta=0.17, p<0.05)$. but not vice versa $(\beta=0.05, p>0.05$; see Figure 2). Thus, there was evidence of a path between depressive symptomatology and social loneliness, and each variable was itself highly stable across waves.

\section{Discussion}

The current investigation found evidence for unidirectional effects of depressive symptomatology and subtypes of loneliness, such that both subtypes were predicted by, but did not predict, depressive symptoms. Strong auto-regressive pathways were also found for both subtypes of loneliness and for depressive symptomatology. The association between depressive symptomatology at baseline and emotional loneliness at follow-up was about half the magnitude of the association between emotional loneliness with itself across waves. The association between depressive symptomatology and social loneliness at follow-up was less than half the size of the autoregressive association within social loneliness. Loneliness has previously been reported to remain quite stable over time in ageing cohort studies, which may suggest that it is at least somewhat trait-like in nature (Shiovitz-Ezra \& Ayalon, 2010).

Results also add to the evidence that loneliness is a multi-dimensional construct (Dahlberg \& McKee, 2014). The finding of a stronger pathway between depressive symptomatology and emotional loneliness, alongside the results of the measurement models for both subtypes of loneliness 
Table 3. Model 1: Auto-regressive and cross-lagged paths (with exogenous covariates age, sex, and perceived stress) for waves 1 and 2 Social Loneliness and Depression, with measurement model components for the latent factors of a) Social Loneliness at Wave 1, and b) Social Loneliness at Wave 2. Robust standard errors were reported throughout.

\begin{tabular}{|c|c|c|c|c|}
\hline & Beta/Factor loading & Standard error & Z & $p$ \\
\hline \multicolumn{5}{|c|}{ Measurement model: Social loneliness At Wave 1} \\
\hline Item 1 & 0.84 & 0.03 & 9.67 & $<0.001$ \\
\hline Item 2 & 0.72 & 0.02 & 10.78 & $<0.001$ \\
\hline Item 3 & 0.68 & 0.03 & 6.24 & $<0.001$ \\
\hline \multicolumn{5}{|l|}{ Social loneliness at Wave 2} \\
\hline Item 1 & 0.76 & 0.03 & 6.86 & $<0.001$ \\
\hline Item 2 & 0.77 & 0.03 & 8.06 & $<0.001$ \\
\hline Item 3 & 0.61 & 0.03 & 5.04 & $<0.001$ \\
\hline \multicolumn{5}{|c|}{ Autoregressive and cross-lagged paths } \\
\hline \multicolumn{5}{|c|}{ Social loneliness (Wave 2) as outcome } \\
\hline Social loneliness at Time 1 & 0.49 & 0.14 & 3.74 & $<0.001$ \\
\hline Depression at Time 1 & 0.17 & 0.01 & 2.35 & $<0.05$ \\
\hline \multicolumn{5}{|c|}{ Depressive symptomatology (Wave 2 ) as outcome } \\
\hline Depressive symptoms at Time 1 & 0.58 & 0.09 & 6.22 & $<0.001$ \\
\hline Social loneliness at Time 1 & 0.05 & 0.25 & 1.002 & $>0.05$ \\
\hline \multicolumn{5}{|c|}{ Regression paths from covariates: With Social loneliness (wave 1) as the outcome } \\
\hline Age & -0.03 & 0.01 & -0.52 & $>0.05$ \\
\hline Education & 0.09 & 0.11 & 1.69 & $>0.05$ \\
\hline Sex & 0.17 & 0.15 & 2.53 & $<0.05$ \\
\hline Social network index & 0.01 & 0.08 & 0.17 & $>0.05$ \\
\hline Comorbidities & 0.09 & 0.25 & 1.19 & $>0.05$ \\
\hline Perceived Stress & 0.31 & 0.03 & 4.04 & $<0.001$ \\
\hline \multicolumn{5}{|c|}{ Regression paths from covariates: With depressive symptomatology (wave 1 ) as the outcome } \\
\hline Age & 0.02 & 0.04 & 0.48 & $>0.05$ \\
\hline Education & -0.07 & 0.45 & -1.60 & $>0.05$ \\
\hline Sex & -0.07 & 0.49 & -1.69 & $>0.05$ \\
\hline Social network index & -0.003 & 0.34 & -0.08 & $>0.05$ \\
\hline Comorbidities & 0.12 & 0.97 & 2.42 & $<0.05$ \\
\hline Perceived Stress & 0.62 & 0.14 & 10.3 & $<0.001$ \\
\hline
\end{tabular}

Wave 1

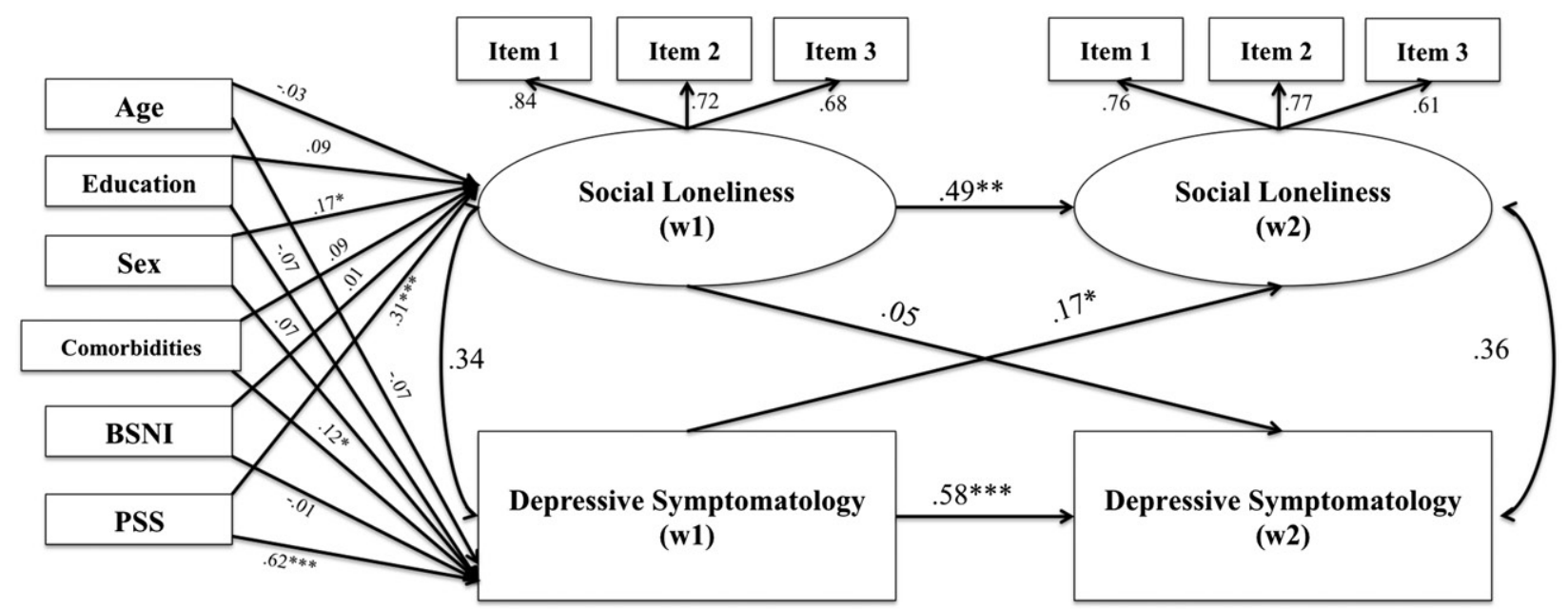

Figure 2. Pathways between baseline and follow-up measures of social loneliness, and depressive symptomatology (all presented statistics except withinwave covariances are standardised coefficients, whereby ${ }^{*}=p<0.05 ; * *=p<0.01 ; * * *=p<0.001$. If no asterisks are attached to the coefficient, it did not reach statistical significance).

(with satisfactory factor loadings), corroborates earlier findings that emotional and social loneliness are separable constructs, with different patterns of predictors (Dahlberg \& McKee, 2014).

Results run counter to suggestions by Weiss that social loneliness rather than emotional loneliness would lead to depression (R. Weiss, 1974) since, in fact, loneliness of neither subtype was found to precede depressive symptomatology. When compared to studies using uni-dimensional definitions of loneliness, our results indicate the same pattern as some (Dahlberg et al., 2015; Drageset et al., 2012; Lasgaard et al., 2011; Mullins \& Dugan, 1990; Tiikkainen \& Heikkinen, 2005) and an opposite pattern to others (Cacioppo et al., 2010; Dahlberg \& McKee, 2014; Heikkinen \& Kauppinen, 2004; O'Luanaigh \& Lawlor, 2008).
Of the mechanisms discussed above, the association between depression and emotional loneliness could be explained with recourse to the impact of depression on attachment, intimacy, and family contact (DiTommaso \& Spinner, 1997; Drennan et al., 2008; Essex et al., 1985; Pettem et al., 1993), all of which would theoretically subserve emotional loneliness (R. S. Weiss, 1973). However, the vast majority of the sample were cohabiting or married, meaning that intimate relationships are unlikely to explain the relationship observed between depressive symptoms and emotional loneliness.

Similarly, associations between depression and social loneliness could be explained as being due to the impact of depression on social withdrawal and disengagement (Allen \& Badcock, 2003; Tiikkainen \& Heikkinen, 2005), all of 
which in turn theoretically subserve social loneliness (R. S. Weiss, 1973). While we did not explore mediators of these associations, we did control for social connectedness, and patterns between depressive symptoms and social loneliness persisted, suggesting that if connectedness mediates this relationship, it is a partial and not a full mediator.

There are a number of methodological weaknesses to be considered before firm conclusions can be drawn from the current study. The design of the study precludes definitive comment on causality. As such, future research using multiple waves of data might strengthen such claims, although without well-designed trials, employing welldefined interventions, all such claims may have to be provisional. The participants were recruited as a convenience sample and as such are not representative of the broader Irish ageing population. The sample was healthy, generally mobile and without significant psychological distress. Levels of loneliness and depressive symptoms appeared to be lower than those found in representative samples studied elsewhere. Further investigations of the crosslagged effects across loneliness and depressive symptomatology should be conducted in more representative populations or in clinical groups with diagnoses of depressive disorders to shed more light on the nature of these relationships. However, we note that in respect of mechanism discovery, even the 'ideal' context of representativeness is contested (Rothman, Gallacher, \& Hatch, 2013). Additionally, we argue that since depressive symptoms and loneliness are conceptualised here as continuous in the population, rather than constituting diagnostic categories, it is still important to consider their associations in this population.

We used a cross-lagged panel modelling approach and followed best practice (Hyland et al., 2015). The diagnostic for determining whether dominating cross-lagged effects exist in the model utilises the information criteria values calculated within a SEM approach. In the current models, these values favoured a model with dominating pathways. We interpret these indices in tandem with the magnitude and significance of the coefficients. As has previously been cautioned, "The clearest answer to the causal directionality question comes when one cross-lagged path is significant but the other is not" (Newsom, 2016). We contend that perhaps the clearest answer to this question ought also to be dependent on the magnitude of the coefficients in the pathways, using statistical significance testing as an additional guideline.

The cross-lagged panel modelling approach involves other methodological considerations. It involves the application of equality constraints to within-wave paths, assuming stationarity of relationships in the models. This means that we assume that the relationship between loneliness and depression in wave 1 did not differ to that in wave 2 . It is possible that these associations do indeed change over time, which would necessitate a more sophisticated modelling approach than that currently used. Furthermore, Hamaker and colleagues have commented that the crosslagged panel model approach is problematic in circumstances where the stability of constructs is attributable to an underlying trait (Hamaker, Kuiper, \& Grasman, 2015). Since some researchers have suggested that loneliness is a trait (Shiovitz-Ezra \& Ayalon, 2010) this may be problematic for the methodological approach taken in the current analysis, and worthy of future investigation. It was not possible to explore the trait nature of loneliness in the current study, which only had two waves of data (Hamaker suggests using three).

Results indicate that individuals who are experiencing depressive symptomatology may be at increased risk of developing symptoms of both social and emotional loneliness over time. Future research using a mediation approach could also investigate whether the mechanisms suggested above might explain how depression leads to increased levels of loneliness, invoking social withdrawal (Allen \& Badcock, 2003), functional impairment (Pinquart \& Sorensen, 2001), and intimacy absences (DiTommaso \& Spinner, 1997; Drennan et al., 2008; Essex et al., 1985; Pettem et al., 1993) as possible mediators.

To date, interventions aimed at alleviating loneliness have met with limited success (Cattan, White, Bond, \& Learmouth, 2005; Masi, Chen, Hawkley, \& Cacioppo, 2011). One possible reason for this may be that studies are targeting "global" loneliness, rather than aiming to reduce levels of emotional or social loneliness, depending on context. We add to existing evidence that emotional and social loneliness are separate constructs, with different patterns of associations to those of uni-dimensional loneliness. This finding should be further explored, particularly in relation to intervention design for loneliness. Additionally, targeting depressive symptoms and reducing these in an ageing population may also decrease the risk of loneliness developing in the future.

\section{Acknowledgements}

The authors wish to thank all participants and staff members at Trinity College Dublin Memory Research Unit, and those at Trinity College Institute of Neuroscience who facilitated data collection. The Memory Research Unit was funded by grants from Atlantic Philanthropies and an Irish Research Council postgraduate scholarship received by $\mathrm{Dr}$ Caoimhe Hannigan. The manuscript was prepared with support from the Centre for Ageing Research and Development in Ireland (CARDI) Leadership in Ageing Research Fellowship received by $\mathrm{Dr}$ Joanna McHugh Power.

\section{Disclosure statement}

No potential conflict of interest was reported by the authors.

\section{ORCID}

Joanna McHugh Power (iD http://orcid.org/0000-0002-7387-3107 Caoimhe Hannigan iD http://orcid.org/0000-0001-8911-2655 Philip Hyland (iD http://orcid.org/0000-0002-9574-7128

Sabina Brennan (D) http://orcid.org/0000-0002-2243-1974

\section{References}

Adams, K. B., Sanders, S., \& Auth, E. (2004). Loneliness and depression in independent living retirement communities: Risk and resilience factors. Aging \& Mental Health, 8(6), 475-485.

Allen, N. B., \& Badcock, P. B. (2003). The social risk hypothesis of depressed mood: Evolutionary, psychosocial, and neurobiological perspectives. Psychological Bulletin, 129(6), 887-913. doi:10.1037/ 0033-2909.129.6.887 
American Psychiatric Association. (2013). Diagnostic and statistical manual of mental disorders (DSM-5®). Arlington, VA: American Psychiatric Pub.

Barrett, A., Burke, H., Cronin, H., Hickey, A., Kamiya, Y., Kenny, R. A., ... Whelan, B. (2011). Fifty Plus in Ireland 2011. The Irish Longitudinal Study on Ageing. http://www.tilda.ie

Berkman, L., \& Syme, S. (1979). Social networks, host resistance, and mortality: A nine-year follow-up study of Alameda County residents. American Journal of Epidemiology, 109(2), 186-204. doi:10.1017/ cbo9780511759048.005

Cacioppo, J. T., Cacioppo, S., \& Boomsma, D. I. (2014). Evolutionary mechanisms for loneliness. Cognition and Emotion, 28(1), 3-21.

Cacioppo, J. T., Ernst, J. M., Burleson, M. H., McClintock, M. K., Malarkey, W. B., Hawkley, L. C., ... Berntson, G. G. (2000). Lonely traits and concomitant physiological processes: The MacArthur social neuroscience studies. International Journal of Psychophysiology, 35, 143-154.

Cacioppo, J. T., Hawkley, L. C., \& Thisted, R. A. (2010). Perceived social isolation makes me sad: 5 year cross-lagged analysis of loneliness and depressive symptomatology in the CHASRS Study. Psychology \& Aging, 25(2), 453-463.

Cacioppo, J. T., Hughes, M. E., Waite, L. J., Hawkley, L. C., \& Thisted, R. A. (2006). Loneliness as a specific risk factor for depressive symptoms: Cross-sectional and longitudinal analyses. Psychology of Aging, 21, 140-151.

Cattan, M., White, M., Bond, J., \& Learmouth, A. (2005). Preventing social isolation and loneliness among older people: A systematic review of health promotion interventions. Ageing and society, 25(01), 41-67.

Christensen, K. J., Moye, J., Armson, R. R., \& Kern, T. M. (1992). Health screening and random recruitment for cognitive ageing research. Psychology and Aging, 7, 204-208.

Cohen, S., Kamarck, T., \& Mermelstein, R. (1983). A global measure of perceived stress. Journal of Health and Social Behaviour, 24(4), 385-396.

Cole, S. R., Kawachi, I., Maller, S. J., \& Berkman, L. F. (2000). Test of item-response bias in the CES-D scale: Experience from the New Haven EPESE study. Journal of Clinical Epidemiology, 53(3), 285-289.

Dahlberg, L., Andersson, L., McKee, K. J., \& Lennartsson, C. (2015) Predictors of loneliness among older women and men in Sweden: A national longitudinal study. Aging \& Mental Health, 19(5), 409-417.

Dahlberg, L., \& McKee, K. J. (2014). Correlates of social and emotional loneliness in older people: Evidence from an English community study. Aging \& Mental Health, 18(4), 504-514.

de Jong Gierveld, J., \& van Tilburg, T. G. (2006). A 6-item scale for overall, emotional, and social loneliness: Confirmatory tests on survey data. Research on Aging, 28(5), 582-598.

DiTommaso, E., \& Spinner, B. (1997). Social and emotional loneliness: A re-examination of Weiss' typology of loneliness. Personality and Individual Differences, 22(3), 417-427.

Donovan, N. J., Wu, Q., Rentz, D. M., Sperling, R. A., Marshall, G. A., \& Glymour, M. M. (2017). Loneliness, depression and cognitive function in older US adults. International Journal of Geriatric Psychiatry, 32(5), 564-573.

Drageset, J., Espehaug, B., \& Kirkevold, M. (2012). The impact of depression and sense of coherence on emotional and social loneliness among nursing home residents without cognitive impairment-a questionnaire survey. Journal of Clinical Nursing, 21(7-8), 965-974.

Drennan, J., Treacy, M., Butler, M., Byrne, A., Fealy, G., Frazer, K., \& Irving, K. (2008). The experience of social and emotional loneliness among older people in Ireland. Ageing \& Society, 28(8), 1113-1132.

Edwards, M. C., Cheavens, J. S., Heiy, J. E., \& Cukrowicz, K. C. (2010). A reexamination of the factor structure of the Center for Epidemiologic Studies Depression Scale: Is a one-factor model plausible? Psychological Assessment, 22(3), 711.

Enders, C. K., \& Tofighi, D. (2008). The impact of misspecifying classspecific residual variances in growth mixture models. Structural Equation Modeling: A Multidisciplinary Journal, 15(1), 75-95.

Essex, M. J., Klein, M. H., Lohr, M. J., \& Benjamin, L. S. (1985). Intimacy and depression in older women. Psychiatry, 48(2), 159-178.

Fried, E. I., Bockting, C., Arjadi, R., Borsboom, D., Amshoff, M., Cramer, A. O. ... Stroebe, M. (2015). From loss to loneliness: The relationship between bereavement and depressive symptoms. Journal of Abnormal Psychology, 124(2), 256.

George, L. K. (1989). Stress, social support, and depression over the life-course. In K. S. Markides \& C. Cooper (Eds.), Aging, Stress and Health (pp. 241-267). Oxford, England: John Wiley \& Sons.

Gierveld, J. D. J., \& Van Tilburg, T. (2010). The De Jong Gierveld short scales for emotional and social loneliness: Tested on data from 7 countries in the UN generations and gender surveys. European Journal of Ageing, 7(2), 121-130.

Green, L. R., Richardson, D. S., Lago, T., \& Schatten-Jones, E. C. (2001) Network correlates of social and emotional loneliness in young and older adults. Personality and Social Psychology Bulletin, 27(3), 281-288.

Hamaker, E. L., Kuiper, R. M., \& Grasman, R. P. (2015). A critique of the cross-lagged panel model. Psychological Methods, 20(1), 102.

Hannigan, C., Coen, R. F., Lawlor, B. A., Robertson, I. H., \& Brennan, S. (2015). The NEIL Memory Research Unit: Psychosocial, biological, physiological, and lifestyle factors associated with healthy ageing: Study Protocol. BMC Psychology, 3(1): 20. doi:10.1186/s40359-0150079-y

Hawkley, L. C., Thisted, R. A., Masi, C. M., \& Cacioppo, J. T. (2010) Loneliness predicts increased blood pressure: Five-year cross-lagged analyses in middle-aged and older adults. Psychology and Aging, 25(1), 132-141.

Heikkinen, R. L., \& Kauppinen, M. (2004). Depressive symptoms in later life: A 10 year follow-up. Archives of Gerontology and Geriatrics, 38(3), 239-250.

Ho, C. S., Feng, L., Fam, J., Mahendran, R., Kua, E. H., \& Ng, T. P. (2014) Coexisting medical comorbidity and depression: Multiplicative effects on health outcomes in older adults. International Psychogeriatrics, 26(7), 1221-1229.

Horowitz, L.M., de French, R. \& Anderson, C.A. (1982). The prototype of a lonely person. In L. Peplau \& D. Perlman (Eds) Loneliness: A sourcebook of current theory, research, and therapy. New York: Wiley and Sons.

Hu, L., \& Bentler, P. M. (1999). Cutoff criteria for fit indexes in covariance structure analysis: Conventional criteria versus new alternatives. Structural Equation Modeling: A Multidisciplinary Journal, 6(1), $1-55$

Hybels, C. F., Pieper, C. F., \& Blazer, D. G. (2009). The complex relationship between depressive symptoms and functional limitations in community-dwelling older adults: The impact of subthreshold depression. Psychological Medicine, 39(10), 1677-1688.

Hyland, P., Shevlin, M., Hansen, M., Vallieres, F., Murphy, J., \& Elklit, A. (2015). The temporal relations of PTSD symptoms among treatment-seeking victims of sexual assault: A longitudinal study Journal of Loss and Trauma, 21(6), 492-506. doi:10.1080/ 15325024.2015.1117933

Lasgaard, M., Goossens, L., \& Elklit, A. (2011). Loneliness, depressive symptomatology, and suicide ideation in adolescence: Cross-sec tional and longitudinal analyses. Journal of Abnormal Child Psychology, 39(1), 137-150.

Liu, L., Gou, Z., \& Zuo, J. (2016). Social support mediates loneliness and depression in elderly people. Journal of Health Psychology, 21(5), 750-758.

Masi, C. M., Chen, H. Y., Hawkley, L. C., \& Cacioppo, J. T. (2011). A meta-analysis of interventions to reduce loneliness. Personality and Social Psychology Review, 15(1), 219-266.

Mehta, K. M., Yaffe, K., \& Covinsky, K. E. (2002). Cognitive impairment, depressive symptoms, and functional decline in older people. Journal of the American Geriatrics Society, 50(6), 1045-1050.

Mullins, L. C., \& Dugan, E. (1990). The influence of depression, and family and friendship relations, on residents' loneliness in congregate housing. Gerontologist, 30(3), 377-384.

Newsom, J. T. (2016). Cross-lagged Panel Analysis. The Encyclopedia of Adulthood and Aging. Hoboken, NJ: Wiley Online.

Nolen-Hoeksema, S., \& Ahrens, C. (2002). Age differences and similarities in the correlates of depressive symptoms. Psychology and Aging, 17(1), 116-124.

O'Luanaigh, C., \& Lawlor, B. A. (2008). Loneliness and the health of older people. International Journal of Geriatric Psychiatry, 23(12) 1213-1221.

Peerenboom, L., Collard, R. M., Naarding, P., \& Comijs, H. C. (2015). The association between depression and emotional and social loneliness in older persons and the influence of social support, cognitive 
functioning and personality: A cross-sectional study. Journal of Affective Disorders, 182(1), 26-31. doi:http://dx.doi.org/10.1016/j.jad. 2015.04.033 Retrieved from http://www.sciencedirect.com/science/ article/pii/S0165032715002578

Perlman, D., \& Peplau, L. A. (1982). Theoretical approaches to loneliness. Loneliness: $A$ sourcebook of current theory, research and therapy (pp. 123-134). New York, NY: Wiley

Pettem, O., West, M., Mahoney, A., \& Keller, A. (1993). Depression and attachment problems. Journal of Psychiatry and Neuroscience, 18(2), 78-81.

Pinquart, M., \& Sorensen, S. (2001). Influences on loneliness in older adults: A meta-analysis. Basic and Applied Social Psychology, 23(4), 245-266.

Radloff, L. (1977). The CES-D Scale: A self report depression scale for research in the general population. Applied Psychological Measurement, 1, 385-401. doi:10.1177/014662167700100306

Rosseel, Y. (2012). lavaan: An R package for structural equation modeling. Journal of Statistical Software, 48(2), 1-36. doi:10.18637/ jss.v048.i02

Rothman, K. J., Gallacher, J. E., \& Hatch, E. E. (2013). Why representativeness should be avoided. International Journal of Epidemiology, 42(1), 1012-1014.

Schnittger, R. I., Wherton, J., Prendergast, D., \& Lawlor, B. A. (2012). Risk factors and mediating pathways of loneliness and social support in community-dwelling older adults. Aging \& Mental Health, 16(3), 335-346.

Shankar, A., McMunn, A., Demakakos, P., Hamer, M., \& Steptoe, A. (2017). Social isolation and loneliness: Prospective associations with functional status in older adults. Health Psychology, 36(2), 179.

Shiovitz-Ezra, S., \& Ayalon, L. (2010). Situational versus chronic loneliness as risk factors for all-cause mortality. International Psychogeriatrics, 22(03), 455-462. doi:10.1017/S1041610209991426 Retrieved from http://dx.doi.org/10.1017/S1041610209991426

Smith, K. J., \& Victor, C. (2018). Typologies of loneliness, living alone and social isolation, and their associations with physical and mental health. Ageing \& Society, 1-22. doi:10.1017/S0144686X18000132
Steptoe, A., Owen, N., Kunz-Ebrecht, S. R., \& Brydon, L. (2004). Loneliness and neuroendocrine, cardiovascular, and inflammatory stress responses in middle-aged men and women. Psychoneuroendocrinology, 29(5), 593-611.

Thomas, A. J., Kalaria, R. N., \& O'Brien, J. T. (2004). Depression and vascular disease: What is the relationship? Journal of Affective Disorders, 79(1), 81-95.

Tiikkainen, P., \& Heikkinen, R.-L. (2005). Associations between loneliness, depressive symptoms and perceived togetherness in older people. Aging \& Mental Health, 9(6), 526-534.

Van Baarsen, B., Snijders, T. A., Smit, J. H., \& Van Duijn, M. A. (2001). Lonely but not alone: Emotional isolation and social isolation as two distinct dimensions of loneliness in older people. Educational and Psychological Measurement, 61(1), 119-135.

van Belijouw, I. M. J., van Exel, E., de Jong Gierveld, J., Comijs, H. C., Heerings, M., Stek, M. L., \& Marwijk, H. W. J. (2014). Being all alone makes me sad: Loneliness in older adults with depressive symptoms. International Psychogeriatrics, 26(9), 1541-1551.

Vanhalst, J., Klimstra, T. A., Luyckx, K., Scholte, R. H., Engels, R. C., \& Goossens, L. (2012). The interplay of loneliness and depressive symptoms across adolescence: Exploring the role of personality traits. Journal of Youth and Adolescence, 41(6), 776-787.

Vanhalst, J., Luyckx, K., Teppers, E., \& Goossens, L. (2012). Disentangling the longitudinal relation between loneliness and depressive symptoms: Prospective effects and the intervening role of coping. Journal of Social and Clinical Psychology, 31(8), 810-834.

Victor, C., \& Bowling, A. (2012). A longitudinal analysis of loneliness among older people in Great Britain. Journal of Psychology: Interdisciplinary and Applied, 146(3), 313-331.

Weeks, D. G., Michela, J. L., Peplau, L. A., \& Bragg, M. E. (1980). Relation between loneliness and depression: A structural equation analysis. Journal of Personality and Social Psychology, 39(6), 1238.

Weiss, R. (1974). The provision of social relationships. In Z. Rubin (Ed.), Doing unto others. New Jersey: Prentice-Hall.

Weiss, R. S. (1973). Loneliness: The experience of emotional and social isolation. Cambridge, MA: The MIT Press. 